\title{
Preliminary analyses of synthetic carbonate plugs: consolidation, petrophysical and wettability properties
}

\author{
Jhonatan Jair Arismendi Florez ${ }^{1,2, *}$ and Jean Vicente Ferrari ${ }^{1}$ \\ ${ }^{1}$ Escola Politécnica da Universidade de São Paulo - Departamento de Engenharia de Minas e Petróleo, Av. Professor Mello Moraes, \\ 2603, 05508-030 São Paulo, Brazil \\ ${ }^{2}$ Poliplugs ${ }^{\circledR}, 05508-030$ São Paulo, Brazil
}

Received: 14 August 2019 / Accepted: 2 November 2020

\begin{abstract}
Synthetic plugs are available to understand oilfield properties and the behavior of oil in reservoirs where natural plugs cannot be extracted. Specifically, in cases where it is necessary to reproduce representative mineralogical and petrophysical characteristics from carbonate reservoirs, it is evident that there is a lack of publications focusing on synthetic plug construction. In this work, a methodology to construct synthetic carbonate plugs is proposed using disintegrated carbonate rock with controlled particle size, mixed in different weight fraction, uniaxial compaction with controlled load force velocity, $\mathrm{pH}$, temperature, and bonding materials. Preliminary analysis of consolidation (basic consolidation and consolidation by water immersion test), wettability (contact angle measurements) and petrophysical properties (nitrogen expansion porosimetry measurements and theoretical porosity calculation) are reported in this study to determine which composition of the synthetic samples provides similar properties compared to that expected for natural rocks from carbonate reservoirs. Two compositions are recommended to construct synthetic samples: Composition 1 with a total quantity of $100 \mathrm{~g}$ of base material $(50 \% \mathrm{w} / \mathrm{w}$ of $<20 \mu \mathrm{m}, 50 \% \mathrm{w} / \mathrm{w}$ of $20-74 \mu \mathrm{m})+5 \% \mathrm{w} / \mathrm{w}$ of amide wax (relative to $100 \mathrm{~g}$ of base material) $+6 \% \mathrm{w} / \mathrm{w}$ (relative to $100 \mathrm{~g}$ of base material) of $\mathrm{pH} 3$ hydrochloric acid solution; and Composition 2 with a total quantity of $100 \mathrm{~g}$ of base material $(50 \% \mathrm{w} / \mathrm{w}$ of $150-300 \mu \mathrm{m}$, $50 \% \mathrm{w} / \mathrm{w}$ of $300-600 \mu \mathrm{m})+5 \% \mathrm{w} / \mathrm{w}$ (relative to $100 \mathrm{~g}$ of base material) of amide wax $+6 \% \mathrm{w} / \mathrm{w}$ (relative to $100 \mathrm{~g}$ of base material) of $\mathrm{pH} 3$ hydrochloric acid solution. In addition to the compositions, it is necessary to follow the reported procedure based on the uniaxial compaction with controlled load force $(200 \mathrm{kN})$ and velocity $(25 \mathrm{~mm} / \mathrm{min})$ and the sample's drying temperature of $100{ }^{\circ} \mathrm{C}$ for $1 \mathrm{~h}$ aiming to obtain similar samples. These preliminary results will guide further dedicated petrophysical and wettability analysis to deeply understanding these sample's properties and enhance the construction of synthetic samples more similar to the natural rocks from carbonate reservoirs.
\end{abstract}

\section{Introduction}

Plugs are rocks with specific dimensions, about 25.4 $38.1 \mathrm{~mm}$ in diameter and a length $1-1.5$ times greater than the diameter, extracted by drilling from petroleum reservoirs. Due to the representative reservoir characteristics such as mineralogical composition, consolidation and petrophysical properties (Cosentino, 2001), plugs can be used at laboratory scale to understand reservoir properties and rock-fluid interactions (Alotaibi et al., 2010; Gaafar et al., 2015).

In some cases, heterogeneous reservoirs and high depths, such as in the Brazilian pre-salt carbonate reservoir, make it challenging to obtain plugs (Barbassa, 2007; Pizarro and Branco, 2012). Due to this challenge, synthetic plugs

\footnotetext{
* Corresponding author: jhonatanarismendi@usp.br
}

(Bernard, 1967; Furre and Holt, 1995; Greaves et al., 1996; Tarek, 2014) manufactured in the laboratory may be used as a closer approximation to the natural plugs from the reservoir, considering their controllable characteristics such as mineralogy and petrophysics (Florez et al., 2019).

To construct synthetic plugs, parameters such as the mineralogical composition of the base material (Lakatos et al., 2003), particle size (Luquot et al., 2016), bonding materials (Celis and Fernandez, 2012), and consolidation methodologies (Wang et al., 1997; Xu and Lu, 2011) may affect the porous media. Plugs may be formed by carbonates or sandstones, which are the main types of rocks in oilfields (Ehrenberg and Nadeau, 2005). These two types of rocks have significant differences, for example, the higher chemical reactivity of the carbonate rocks due to the carbonate mineral (Pizarro and Branco, 2012). In contrast to the sandstone reservoirs (Anbah et al., 1965; Raimondi 
and Torcaso, 1964; Wang et al., 2008), there is a lack of publications that focus on the construction of representative synthetic carbonate plugs that consider both mineralogical composition and petrophysical properties as highlighted by Florez et al. (2019). The authors presented a literature review classifying a selected group of publications, a total of 81 papers and reports published from 1962 to 2016. From here, regarding the approach for the construction of carbonate plugs, the authors reported only one paper using calcite flour $(95 \% \mathrm{w} / \mathrm{w})$ as the carbonate matrix. However, petrophysical analyses regarding controlled porous structures were not reported.

In addition to the information reported by Florez et al. (2019), some recent works were found from 2017 to 2019, aiming at the same approach (Fedrizzi et al., 2018; Luo et al. 2018; Wang et al. 2017). Wang et al. (2017), during the construction process, embedded $\mathrm{NaCl}$ grains (1.45, $1.66,2.9$ and $5.8 \mathrm{~g}$ ) of average particle size of $3 \mathrm{~mm}$ and aluminum (18, 27, 36 and 45 foils) with radius of $1.5 \mathrm{~mm}$ and a thickness of $20 \mu \mathrm{m}$ into a blend of mass ratio 50:1 composed of carbonate drilling cuttings with average grain size of $120 \mu \mathrm{m}$ and epoxy resin (epoxy type GCC135 and curing agent W93). Then, the embedded materials were leached out by immersing the consolidated synthetic plug in an alkali solution of $4 \% \mathrm{w} / \mathrm{w} \mathrm{NaOH}$ (sodium hydroxide) at $75{ }^{\circ} \mathrm{C}$. The authors observed by Scanning Electron Microscope (SEM) images and Computed Tomography Images $(\mathrm{CT})$ that $\mathrm{NaCl}$ grains and aluminum foils form vuggy and crack pores respectively, which are essential parameters to control the permeability of the plugs. The higher the $\mathrm{NaCl}$ content, the higher the porosity, and the higher the permeability. The higher the aluminum content, the higher porosity, and the lower the permeability. However, it is necessary to develop a better understanding of the pore structure and the influence of the quantity of epoxy resin and particle size drilling cuttings in the petrophysical properties. Additionally, the chemical nature of epoxy resin as bonding material could change the chemical properties of the constructed samples, a fact that can affect the fluid-rock interaction tests such as wettability measurements.

Fedrizzi et al. (2018) reported the construction of carbonate rocks using aggregates (calcite and sand), Portland cement $(20,30,40,50,60 \% \mathrm{w} / \mathrm{w}$ relative to the aggregates' weight) and water $(10,15,20,30,40 \% \mathrm{w} / \mathrm{w}$ relative to the aggregates' weight). In this work, the main basic petrophysical characteristics of these samples (porosity and absolute permeability) and the relationship with the amount of cementing material were investigated. Despite the points of similarity that the authors show of the constructed samples with the carbonate rocks (chemical and petrophysical), the construction of representative synthetic carbonate plugs also requires the characterization of rock-fluid interaction.

Luo et al. (2018) cleaned drill cuttings using a solution of $3 \% \mathrm{w} / \mathrm{w} \mathrm{KCl}$ under high agitation and then dried them in an oven at a constant temperature of $60{ }^{\circ} \mathrm{C}$ and $45 \%$ humidity. Then, they were placed into a cylindrical pipe with toluene, and pressure of 5000 psi was applied for $30 \mathrm{~min}$ to consolidate the synthetic plugs. These resultant plugs were used for studying formation damage. Petrophysical properties, influence of the compression press and drill cutting particles on the properties of the constructed synthetic plugs were not studied in this work. However, despite the mineralogical properties of the constructed plugs being similar to that found in a specific field, these synthetic plugs do not guarantee the reproduction and control of similar petrophysical properties of natural plugs.

Florez et al. (2019) proposed the construction of synthetic carbonate plugs, using a procedure based on pulverized rock matrices as base material with known particle size (0.3-0.6 mm, 0.15-0.3 mm, 0.074-0.15 mm, 0.020 $0.074 \mathrm{~mm},<0.02 \mathrm{~mm})$, uniaxial compaction $(200 \mathrm{kN}$ load force, compression velocity of $25 \mathrm{~mm} / \mathrm{min}$ ), probable $\mathrm{CaCO}_{3}$ solubility by acid $\mathrm{pH}(6 \% \mathrm{w} / \mathrm{w})$ and drying temperature $\left(100{ }^{\circ} \mathrm{C}\right)$. The work illustrated promising results to simulate carbonate rock matrices and consolidated plugs to perform basic petrophysical tests. However, this study did not take into account the analysis of the consolidation on fluids and a more systematic approach regarding both basic petrophysical properties (porosity and permeability) and advanced ones (wettability) which are necessary to guarantee controlled physical and chemical properties similar to natural carbonate plugs.

The present study proposes the construction of synthetic carbonate plugs with physical and chemical properties that can be easily controlled with the aim of reproducing the following parameters: wettability of the natural carbonate rock which, in measures of contact angle, corresponds with the angles of water droplets in the air between $50-80^{\circ}$ for surfaces with intermediate wettability and values above $80^{\circ}$ correspond to surfaces wettable by oil (Grate et al., 2012); porosities, as evidenced by the National Agency of Petroleum (ANP) for the carbonate reservoirs of the Brazilian pre-salt range in between $6 \%$ and $28 \%$ and permeability, ranges between 0.1 and $10000 \mathrm{mD}$ (ANP, 2018a, 2018b, 2018c, 2018d, 2018e, 2018f, 2018g, 2018h, 2018i); grain density reported in the literature for dolomite rock of $2.84 \mathrm{~g} / \mathrm{cm}^{3}$ (Dolomite Mineral Data, 2018).

\section{Experimental section}

\subsection{Materials}

The base material used in this work to construct synthetic plugs was a disintegrated dolomitic carbonate rock from outcrop with controlled particle size. Based on the known increase in calcium carbonate solubility relative to medium acidity, $\mathrm{pH} 3$ hydrochloric acid solution was mixed with this base material $(6 \% \mathrm{w} / \mathrm{w}$ relative to the base material). In this way, a dissolution of base material followed by precipitation by applying temperature contributed to the consolidation of samples (Florez et al., 2019). Additionally, samples were constructed with or without bonding materials to study the enhancement of the consolidation. The proportions used of these bonding materials were $5 \% \mathrm{w} / \mathrm{w}$ and $10 \% \mathrm{w} / \mathrm{w}$ relative to the base material. Table 1 reports the materials used to construct synthetic plugs. 
Table 1. Materials and its content used to construct disk geometry samples and real size plugs.

\begin{tabular}{|c|c|c|}
\hline Function & Description & Content \\
\hline Base material & $\begin{array}{l}\text { Disintegrated dolomitic carbonate } \\
\text { rock grain density } \\
\text { of } 2.87 \mathrm{~g} / \mathrm{cm}^{3}\end{array}$ & $5 \mathrm{~g}\left(2.5 \mathrm{~cm}^{3}\right)$ or $100 \mathrm{~g}\left(34.8 \mathrm{~cm}^{3}\right)$ \\
\hline Carbonate solubilization & pH 3 hydrochloric acid solution & $6 \% \mathrm{w} / \mathrm{w}(17.22 \% \mathrm{v} / \mathrm{v})$ relative to the base material \\
\hline \multirow[t]{4}{*}{ Bonding materials } & $\begin{array}{l}\text { Slow setting gypsum powder } \\
\text { (specific gravity of } 2.96 \text { ) }\end{array}$ & $\begin{array}{l}5 \% \mathrm{w} / \mathrm{w}(4.9 \% \mathrm{v} / \mathrm{v}) \text { relative to the base material } \\
10 \% \mathrm{w} / \mathrm{w}(9.7 \% \mathrm{v} / \mathrm{v}) \text { relative to the base material }\end{array}$ \\
\hline & $\begin{array}{l}\text { Fast setting gypsum powder } \\
\text { (specific gravity of } 2.96 \text { ) }\end{array}$ & $\begin{array}{l}5 \% \mathrm{w} / \mathrm{w}(4.9 \% \mathrm{v} / \mathrm{v}) \text { relative to the base material } \\
10 \% \mathrm{w} / \mathrm{w}(9.7 \% \mathrm{v} / \mathrm{v}) \text { relative to the base material }\end{array}$ \\
\hline & $\begin{array}{l}\text { Stearic acid powder } \\
\text { (specific gravity of } 0.94 \text { ) }\end{array}$ & $\begin{array}{l}5 \% \mathrm{w} / \mathrm{w}(15.3 \% \mathrm{v} / \mathrm{v}) \text { relative to the base material } \\
10 \% \mathrm{w} / \mathrm{w}(30.5 \% \mathrm{v} / \mathrm{v}) \text { relative to the base material }\end{array}$ \\
\hline & $\begin{array}{l}\text { Commercial amide wax of type } N, \\
N \text {-bis-stearyl ethylenediamine } \\
\text { (specific gravity of 1.0) }\end{array}$ & $\begin{array}{l}5 \% \mathrm{w} / \mathrm{w}(14.4 \% \mathrm{v} / \mathrm{v}) \text { relative to the base material } \\
10 \% \mathrm{w} / \mathrm{w}(28.7 \% \mathrm{v} / \mathrm{v}) \text { relative to the base material }\end{array}$ \\
\hline
\end{tabular}

Table 2. Properties of the mineral oil used as oil droplets in the contact angle equipment.

\begin{tabular}{lc}
\hline Property & Description \\
\hline Specific weight at $25{ }^{\circ} \mathrm{C}\left(\mathrm{g} / \mathrm{cm}^{3}\right)$ & $0.828-0.856$ \\
Kinematic viscosity at $40{ }^{\circ} \mathrm{C}(\mathrm{cP})$ & $8.9424-11.856$ \\
Flash point $\left({ }^{\circ} \mathrm{C}\right)$ & $>140$ \\
\hline
\end{tabular}

In the case of wettability measurements, distilled water and mineral oil were used as droplets in the contact angle equipment. Properties of the mineral oil are reported in Table 2.

\subsection{Base material preparation}

Before testing, carbonate rock from outcrop was cleaned by using distilled water. The chemical composition of the dolomitic carbonate rock from outcrop used as base material to construct the synthetic samples was checked by using X-ray spectrometry fluorescence in the STD-1 (Standardless) calibration. The Loss On Ignition (LOI) test was carried out at $1020^{\circ} \mathrm{C}$ for $2 \mathrm{~h}$. To construct the synthetic plugs, the base material was disintegrated first by a jaw crusher BM 2010 and then by a roller crusher Furlan MR2515 with roller openings between 2 and $6 \mathrm{~mm}$. Then, micron particle sizes from the disintegrated rock were sorted by using an electromagnetically driven 3D sieve shaker Haver EML digital plus for $20 \mathrm{~min}$, in intervals of $15 \mathrm{~s}$ and wavelength of 14 . The obtained particle size intervals were: $300-600 \mu \mathrm{m}, 150$ $300 \mu \mathrm{m}, 74-150 \mu \mathrm{m}$ and $20-74 \mu \mathrm{m}$. Besides, samples of particle size of 20-74 $\mu \mathrm{m}$ were pulverized for $2 \mathrm{~min}$ in a Herzog pulverizer and then sorted in the same Haver EML digital plus for $20 \mathrm{~min}$, in intervals of $15 \mathrm{~s}$ and wavelength of 14 to obtain particle size of $<20 \mu \mathrm{m}$. Finally, samples from the five particle size intervals were put into the automatic feeder of the Camsizer-XT (CAM) equipment where particle size distribution and particle shape were analyzed by dynamic image from low angle laser light scattering measurements.

\subsection{Methodology to construct synthetic plugs}

Two kinds of samples were constructed: samples of disk geometry (by using a total quantity of $5 \mathrm{~g}$ of base material) and samples of plug geometry (by using a total quantity of $100 \mathrm{~g}$ of base material). To prepare these samples, the previously sorted base material was preweighed and mixed in weight fractions of $50 \% \mathrm{w} / \mathrm{w}: 50 \% \mathrm{w} / \mathrm{w}, 33.3 \% \mathrm{w} / \mathrm{w}$ : $66.7 \% \mathrm{w} / \mathrm{w}$ or $25 \% \mathrm{w} / \mathrm{w}: 75 \% \mathrm{w} / \mathrm{w}$ relative to the total quantity of base material. Afterward, bonding materials (if used) and $\mathrm{pH} 3$ hydrochloric acid solution percentages $(\% \mathrm{w} / \mathrm{w}$ relative to the total quantity of base material, $5 \mathrm{~g}$ or $100 \mathrm{~g}$ ) were based on the base material and homogenized by hand-mixing using a spatula. The samples were manufactured through five different approaches (experiments) detailed hereafter. Table S1 shows the composition and approaches of each sample. After 1 min of mixing, the resulting blend was placed inside a cylindrical metallic vessel, with dimensions of $3.77 \mathrm{~cm}$ internal diameter, $3.00 \mathrm{~cm}$ thickness, and $13.00 \mathrm{~cm}$ height and the dimensions of the piston were $3.75 \mathrm{~cm}$ diameter and $15.90 \mathrm{~cm}$ height. Previously, the internal chamber was lubricated with an ethyl alcohol solution containing $1 \% \mathrm{w} / \mathrm{w}$ stearic acid powder. Then, a load of $200 \mathrm{kN}$ was applied with a controlled velocity of $25 \mathrm{~mm} / \mathrm{min}$. Subsequently, the resulting consolidated sample was placed for $1 \mathrm{~h}$ into an oven with air circulation at $100{ }^{\circ} \mathrm{C}$ to guarantee a drier and higher consolidation based on $\mathrm{CaCO}_{3}$ solubility and precipitation by temperature. Photographic register of the samples was taken at 0,1 , and $120 \mathrm{~h}$ after removal from compression molding. Finally, the samples were cooled down to ambient temperature (from 27 to $30^{\circ} \mathrm{C}$ ) for use for testing.

\subsection{Experiments}

Preliminary analyses of consolidation, wettability and petrophysics are reported in this study to determine which composition of the synthetic samples provides similar 
properties compared to that expected for natural rocks from carbonate reservoirs.

\subsubsection{Basic consolidation test}

This experiment was used to observe the changes such as fractures or breaks caused in the samples after being handled by an operator. This approach allows to determine which sample composition provides the greatest consolidation in terms of structural integrity. The visual changes were registered by photographing samples at 0,1 and $120 \mathrm{~h}$ after removal from compression molding.

\subsubsection{Consolidation by water immersion test}

The main aim was to verify if such samples would not have disintegrated in this medium. One hundred and twenty hours after removal from compression molding, samples were placed into a glass flask which was then filled with distilled water and submitted to room temperature (from 27 to $30{ }^{\circ} \mathrm{C}$ ) and pressure during $12 \mathrm{~h}$. The visual changes of the structural integrity were registered by photographing samples at 0 and $12 \mathrm{~h}$ during the test and $1 \mathrm{~h}$ after being removed from water.

\subsubsection{Basic wettability test}

The objective of this measure was to study preliminarily the wettability of the surface of the synthetic samples. This basic test allows to determine which sample composition provides similar wettability behavior compared to natural rocks from carbonate reservoirs in order to guide further dedicated wettability tests such as the Amott-Harvey index. Measurements were done on samples with disk and plug geometries, using a DSA 100 Kruss drop shape analyzer at room pressure $(14.7 \mathrm{psi})$ and temperature $\left(24^{\circ} \mathrm{C}\right)$. A droplet of distilled water or mineral oil was placed on the flat surface of the sample, and the contact angle was measured immediately $(0 \mathrm{~s})$ and after $10 \mathrm{~s}$. Tests were applied to samples $120 \mathrm{~h}$ after removal from compression molding.

\subsubsection{Basic petrophysical test}

Porosity, absolute permeability and grain density were studied to guarantee similar properties of the synthetic samples of plug geometry compared to natural carbonate rocks from reservoirs. Samples of plug geometry were submitted to nitrogen expansion porosimetry measurements. Before the test, synthetic plugs were dried for $24 \mathrm{~h}$ in an oven at $60{ }^{\circ} \mathrm{C}$ with controlled humidity of $45 \%$. A confinement pressure of 2400 psi was used in an Ultrapore 300 porosimeter and Ultraperm 500 permeameter, both from Corelab. The Klinkenberg effect was corrected to obtain the porosity and permeability results (Tanikawa and Shinamoto, 2006). Tests were applied to samples $120 \mathrm{~h}$ after removal from compression molding.

\subsubsection{Theoretical porosity calculation}

In addition to gas petrophysical tests, theoretical porosity was used as a reference value to the expected porosity in the samples of plug geometry to compare experimental and theoretical values and calculate the deviation of the porosity. Theoretical porosity was calculated using the following equations (Lowell et al., 2004).

- Calculation of the volume of the synthetic plugs, based on the measured diameters and heights, using equation (1). $v$ is the volume of the synthetic plug in $\mathrm{cm}^{3}, d$ is the measured diameter of the synthetic plug in $\mathrm{cm}$, and $h$ is the measured height of the synthetic plug in $\mathrm{cm}$,

$$
v=\frac{\pi d^{2} h}{4}
$$

- Calculation of the mass of the previously calculated volume of the synthetic plugs, considering this as a homogeneous solid without porosity, using equation (2). $m s$ is the mass in $\mathrm{g}$ of the synthetic plug, considering it as a homogeneous solid without porosity, $v$ is the volume of the sample calculated by equation (1) in $\mathrm{cm}^{3}$, and $\rho$ is the average grain density of the synthetic plug in $\mathrm{g} / \mathrm{cm}^{3}$,

$$
m s=v \rho .
$$

- Calculation of the empty mass in the synthetic plug, considered as porous, using equation (3). $\mathrm{mp}$ is the missing mass in $\mathrm{g}$ in the synthetic plug, considered as porous, $m s$ is the mass in $g$ of the synthetic plug considered as a homogenous solid without porosity, calculated by equation (2), and $m$ is the measured mass of the synthetic plug in $\mathrm{g}$.

$$
m p=m s-m .
$$

- Calculation of the volume that should be occupied by the missing mass in the synthetic plug, considered as porous volume, using equation (4). vp is the calculated porous volume in $\mathrm{cm}^{3}, \mathrm{mp}$ is the missing mass in $\mathrm{g}$ in the synthetic plug, considered as porous and calculated by equation (3), and $\rho$ is the average grain density of the synthetic plug in $\mathrm{g} / \mathrm{cm}^{3}$,

$$
v p=\frac{m p}{\rho} .
$$

- Calculation of the expected porosity o the synthetic plug, using equation (5). $\emptyset$ is the expected porosity as a percentage, $v p$ is the porous volume calculated by equation (4) in $\mathrm{cm}^{3}$, and $v$ is the volume of the synthetic plug in $\mathrm{cm}^{3}$ calculated by equation (1),

$$
\emptyset=\frac{v p}{v} \times 100 \text {. }
$$

\section{Results and discussion}

\subsection{Construction of the samples with disk geometry}

The chemical composition of the dolomitic carbonate rock from outcrop is reported in Table 3. Concerning the 
Table 3. Chemical composition of the dolomitic carbonate rock used as base material to construct the synthetic samples.

\begin{tabular}{|c|c|}
\hline Chemical composition & Weight fraction (\%) \\
\hline $\mathrm{Na}_{2} \mathrm{O}$ & $<0.001$ \\
\hline $\mathrm{MgO}$ & 15.5 \\
\hline $\mathrm{Al}_{2} \mathrm{O}_{3}$ & 0.765 \\
\hline $\mathrm{SiO}_{2}$ & 4.51 \\
\hline $\mathrm{P}_{2} \mathrm{O}_{5}$ & 0.014 \\
\hline $\mathrm{SO} 3$ & 0.033 \\
\hline $\mathrm{Cl}$ & 0.021 \\
\hline $\mathrm{K}_{2} \mathrm{O}$ & 0.064 \\
\hline $\mathrm{CaO}$ & 36.4 \\
\hline $\mathrm{TiO}_{2}$ & 0.043 \\
\hline $\mathrm{Cr}_{2} \mathrm{O}_{3}$ & 0.011 \\
\hline $\mathrm{MnO}$ & 0.103 \\
\hline $\mathrm{Fe}_{2} \mathrm{O}_{3}$ & 0.564 \\
\hline $\mathrm{NiO}$ & $<0.001$ \\
\hline $\mathrm{ZnO}$ & 0.024 \\
\hline $\mathrm{SrO}$ & 0.018 \\
\hline $\mathrm{ZrO}_{2}$ & 0.044 \\
\hline $\mathrm{Nb}_{2} \mathrm{O}_{5}$ & 0.029 \\
\hline LOI & 41.9 \\
\hline
\end{tabular}

analysis of chemical elements between fluorine and uranium, higher concentrations of $\mathrm{CaO}(36.4 \%), \mathrm{MgO}$ $(15.5 \%), \mathrm{SiO}_{2}(4.51 \%)$ and LOI $(41.9 \%)$ were observed, which according to Souza and Bragança (2013) and Dolomite Mineral Data (2018) corresponds to a dolomitic carbonate sample.

From the base material preparation, five particle size intervals were obtained: $300-600 \mu \mathrm{m}, \quad 150-300 \mu \mathrm{m}$, 74-150 $\mu \mathrm{m}, 20-74 \mu \mathrm{m}$ and $<20 \mu \mathrm{m}$. Figure 1 presents photographs of these resulting particle size intervals where no changes in color of the particles were observed.

From the Camsizer-XT equipment, particle size distribution expressed as minimum particle diameter (xc min) and particle morphology expressed in $\mathrm{b} / \mathrm{l}$ and $\mathrm{SP} \overline{\mathrm{HT}}$ of the five particle size intervals were obtained and are presented in Table 4.

Comparing particle size distribution $D[10], D[50], D[90]$ and $\mathrm{D}$ averages from the analyzed disintegrated dolomitic carbonate rock, the similar particle size intervals obtained by sieve and CAM measurements were corroborated. Additionally, a tendency to obtain higher SPHT and b/1 values with the decrease of particle size was observed. Probably, this behavior can be correlated to the mechanical disintegration of the rock by the jaw and roller crusher.

\subsection{Basic consolidation test of samples of disk geometry constructed without using bonding materials}

Samples D1-D30 of disk geometry (total quantity of $5 \mathrm{~g}$ of base material for each sample) were constructed aiming to observe the basic consolidation of the samples by mixing the base material with controlled particle size in the three weight fractions: $50 \% \mathrm{w} / \mathrm{w}: 50 \% \mathrm{w} / \mathrm{w}, 33.3 \% \mathrm{w} / \mathrm{w}: 66.7 \%$ $\mathrm{w} / \mathrm{w}, 25 \% \mathrm{w} / \mathrm{w}: 75 \% \mathrm{w} / \mathrm{w}$; adding $6 \% \mathrm{w} / \mathrm{w}$ (relative to $5 \mathrm{~g}$ of base material) of $\mathrm{pH} 3$ hydrochloric acid solution for each sample. No bonding materials were used.

Figures S1-S3 in the Supplementary Material present all the constructed samples of disk geometry, at 0,1 and $120 \mathrm{~h}$ after the fconsolidation process. Figure 2 presents some of the resulting disks to illustrate the following analysis. The same tendency to improved consolidation behavior by decreasing particle size reported by Florez et al. (2019) was corroborated, even mixing particles of different sizes (Fig. 2a). The use of a higher coarse particle content reduces the material agglomeration, worsening the consolidation of samples. The possibility of consolidation of the coarse particle size when mixed with the finest particle size using the same weight fraction $(50 \% \mathrm{w} / \mathrm{w}: 50 \% \mathrm{w} / \mathrm{w})$, worsening with the increase of the content of coarse particles in the weight fraction $(33.3 \% \mathrm{w} / \mathrm{w}: 66.7 \% \mathrm{w} / \mathrm{w}$ and $25 \% \mathrm{w} / \mathrm{w}$ : $75 \% \mathrm{w} / \mathrm{w}$ ) was also noted. It represents an improvement in the methodology used by Florez et al. (2019), where samples composed of only coarse particles showed poor consolidation. Sample $D 1$ showed the best consolidation. Figure $2 \mathrm{~b}$ presents an example of the consolidation behavior of the resultant samples composed of D4 $(50 \% \quad \mathrm{w} / \mathrm{w}$ of $<20 \mu \mathrm{m}: 50 \% \mathrm{w} / \mathrm{w}$ of $300-600 \mu \mathrm{m}), \mathrm{D} 14(33.3 \% \mathrm{w} / \mathrm{w}$ of $<20 \mu \mathrm{m}: 66.7 \% \mathrm{w} / \mathrm{w}$ of $300-600 \mu \mathrm{m})$ and D24 $(25 \% \mathrm{w} / \mathrm{w}$ of $<20 \mu \mathrm{m}: 75 \% \mathrm{w} / \mathrm{w}$ of $300-600 \mu \mathrm{m}) 120 \mathrm{~h}$ after removal from compression molding.

\subsection{Consolidation by water immersion test of the samples with disk geometry constructed without using bonding materials}

Subsequent to the basic consolidation test, the water immersion test was carried out in the sample D31 which has the same composition of the sample with the best basic consolidation evaluated previously (D1). The composition of this sample was: a total quantity of $5 \mathrm{~g}$ of base material composed in weight fraction by $50 \% \mathrm{w} / \mathrm{w}$ of $<20 \mu \mathrm{m}$ and $50 \% \mathrm{w} / \mathrm{w}$ of $20-74 \mu \mathrm{m} ; 6 \% \mathrm{w} / \mathrm{w}$ (relative to $5 \mathrm{~g}$ of base material) of $\mathrm{pH} 3$ hydrochloric acid solution, and no bonding materials were used.

From there, as presented in Figure 3, it was noted that the previously proposed methodology by Florez et al. (2019) does not guarantee a great consolidation of the samples when immersed in a water medium, probably due to the weak consolidation caused by the solubility (by using the acid solution in the construction processes) and precipitation (by submitting samples to temperature of $100{ }^{\circ} \mathrm{C}$ during the construction process) of the base material $\left(\mathrm{CaCO}_{3}\right)$.

\subsection{Basic wettability tests of the samples with disk geometry constructed without using bonding materials}

To evaluate the wettability behavior due to different particle sizes and particle size ratios, contact angle measurements were carried out in samples D32-D37 with the finest $(<20 \mu \mathrm{m}$ and $20-74 \mu \mathrm{m})$ and thickest $(150-300 \mu \mathrm{m}$ 


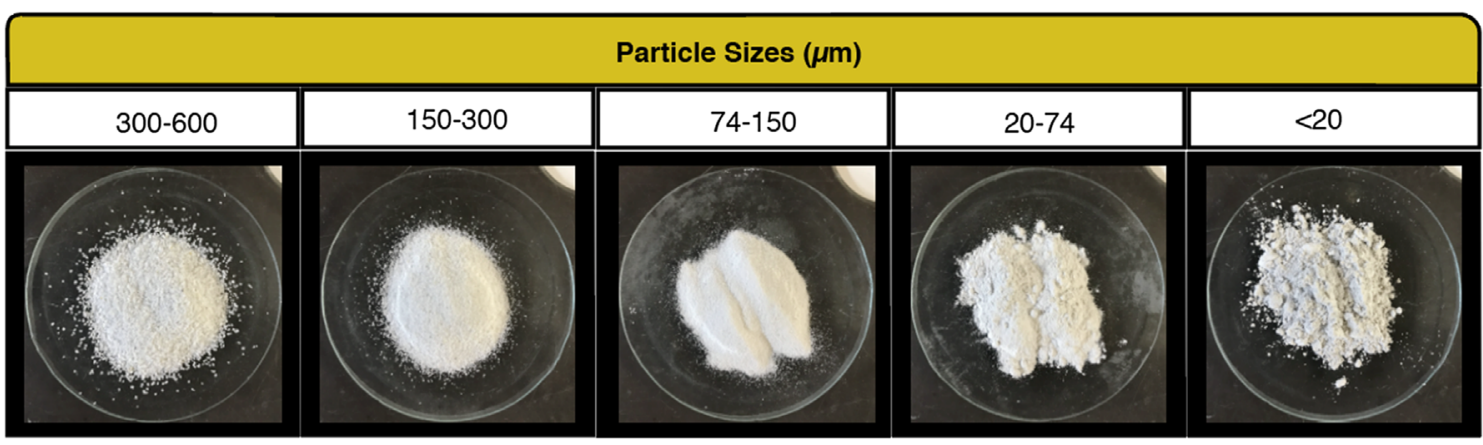

Fig. 1. Resulting particle size. From coarse (left) to fine (right) 300-600 $\mu \mathrm{m}, 150-300 \mu \mathrm{m}, 74-150 \mu \mathrm{m}, 20-74 \mu \mathrm{m}$ and $<20 \mu \mathrm{m}$.

Table 4. Particle size distribution and morphology of the five particle size intervals.

\begin{tabular}{lcccccc}
\hline \multirow{2}{*}{$\begin{array}{l}\text { Particle size intervals } \\
\text { by sieve }(\mu \mathrm{m})\end{array}$} & \multicolumn{5}{c}{ Particle size distribution and morphology obtained from Camsizer-XT equipment } \\
\cline { 2 - 6 } & $D[10](\mu \mathrm{m})$ & $D[50](\mu \mathrm{m})$ & $D[90](\mu \mathrm{m})$ & $D$ average $(\mu \mathrm{m})$ & SPHT average & $\mathrm{b} /$ average \\
\hline $300-600$ & 312.9 & 448.6 & 609.4 & 452.6 & 0.777 & 0.651 \\
$150-300$ & 130.2 & 215.6 & 317.9 & 219.8 & 0.790 & 0.649 \\
$74-150$ & 41.9 & 97.0 & 149.3 & 96.7 & 0.835 & 0.690 \\
$20-74$ & 11.2 & 34.6 & 73.2 & 34.3 & 0.846 & 0.721 \\
$<20$ & 0.6 & 2.9 & 17.8 & 3.2 & 0.869 & 0.726 \\
\hline
\end{tabular}

and $300-600 \mu \mathrm{m})$ combination of particle size previously used during the basic consolidation test. A total quantity of $5 \mathrm{~g}$ of base material for each sample was composed in weight fraction, adding $6 \% \mathrm{w} / \mathrm{w}$ (relative to $5 \mathrm{~g}$ of base material) of $\mathrm{pH} 3$ hydrochloric acid solution, and no bonding materials were used (see Tab. S1).

The measurements of basic wettability are presented in Figure 4. For the distilled water droplet and the mineral oil droplet, it was observed that there is a tendency to decrease the contact angles during the first $10 \mathrm{~s}$ after placing these droplets on the flat surface of the samples, except for samples with the thickest particle size in the three weight fractions where water droplet contact angle values of zero were observed over time. Additionally, all samples showed higher contact angles for oil droplets when compared with water droplets.

Probably, absorption of water droplets by the sample influenced the measurements: a contact angle of zero was influenced by this absorption instead of the spreading of the water droplets. This is in contrast to the oil droplet behavior in which no uptake was observed. From these preliminary results, such samples are not appropriate due to the water uptake issue.

\subsection{Construction and basic consolidation test of the samples with disk geometry composed by bonding materials}

Due to the challenge previously noted, it was necessary to improve the consolidation methodology aiming for better basic consolidation, better consolidation in water medium and wettability behavior similar to natural carbonates from a reservoir. To this end, samples D38-D45 were constructed using the same composition of the sample with the best basic consolidation evaluated previously and adding bonding materials presented in Table 1 . Small weight fractions $(5 \% \mathrm{w} / \mathrm{w}$ and $10 \% \mathrm{w} / \mathrm{w}$ relative to the base material) of the bonding materials were used, so that the main carbonate mineralogy would be predominant.

Samples of disk geometry were composed by: the same quantity of base material $(5 \mathrm{~g})$, same weight fraction of combined particle size $(50 \% \mathrm{w} / \mathrm{w}$ of $<20 \mu \mathrm{m}, 50 \% \mathrm{w} / \mathrm{w}$ of 20-74 $\mu \mathrm{m}$ ), same quantity of $\mathrm{pH} 3$ hydrochloric acid solution $(6 \% \mathrm{w} / \mathrm{w}$ relative to $5 \mathrm{~g}$ of base material) and different weight fractions of bonding materials $(5 \% \mathrm{w} / \mathrm{w}$ or $10 \% \mathrm{w} / \mathrm{w}$ relative to $5 \mathrm{~g}$ of base material). Sample D38 (5\% of slow setting gypsum), Sample D39 (10\% of slow setting gypsum), Sample D40 (5\% of fast setting gypsum); Sample D41 (10\% of fast setting gypsum); Sample D42 (5\% of stearic acid); Sample D43 (10\% of stearic acid); Sample D44 ( $5 \%$ of amide wax); Sample D 45 (10\% of amide wax).

Figure S4 in the Supplementary Material presents all the constructed samples of disk geometry, at 0, 1 and $120 \mathrm{~h}$ after the consolidation process. Figure 5 presents the resulting disks $120 \mathrm{~h}$ after removing samples from compression molding to illustrate the following analysis. It was possible to observe that samples composed by slow and fast setting gypsum presented fractures on their structures. In contrast, samples constructed using stearic acid and commercial amide wax presented better consolidation. 


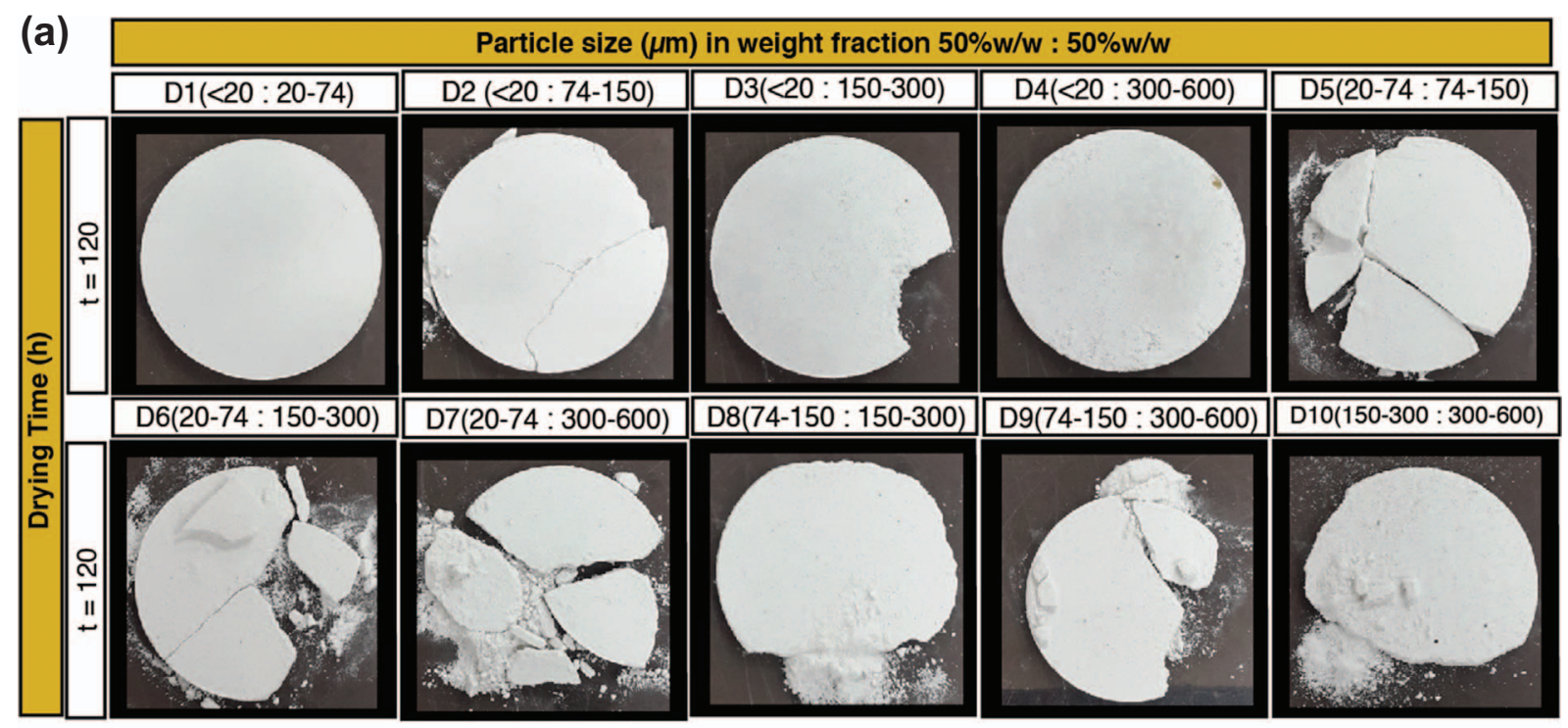

(b)
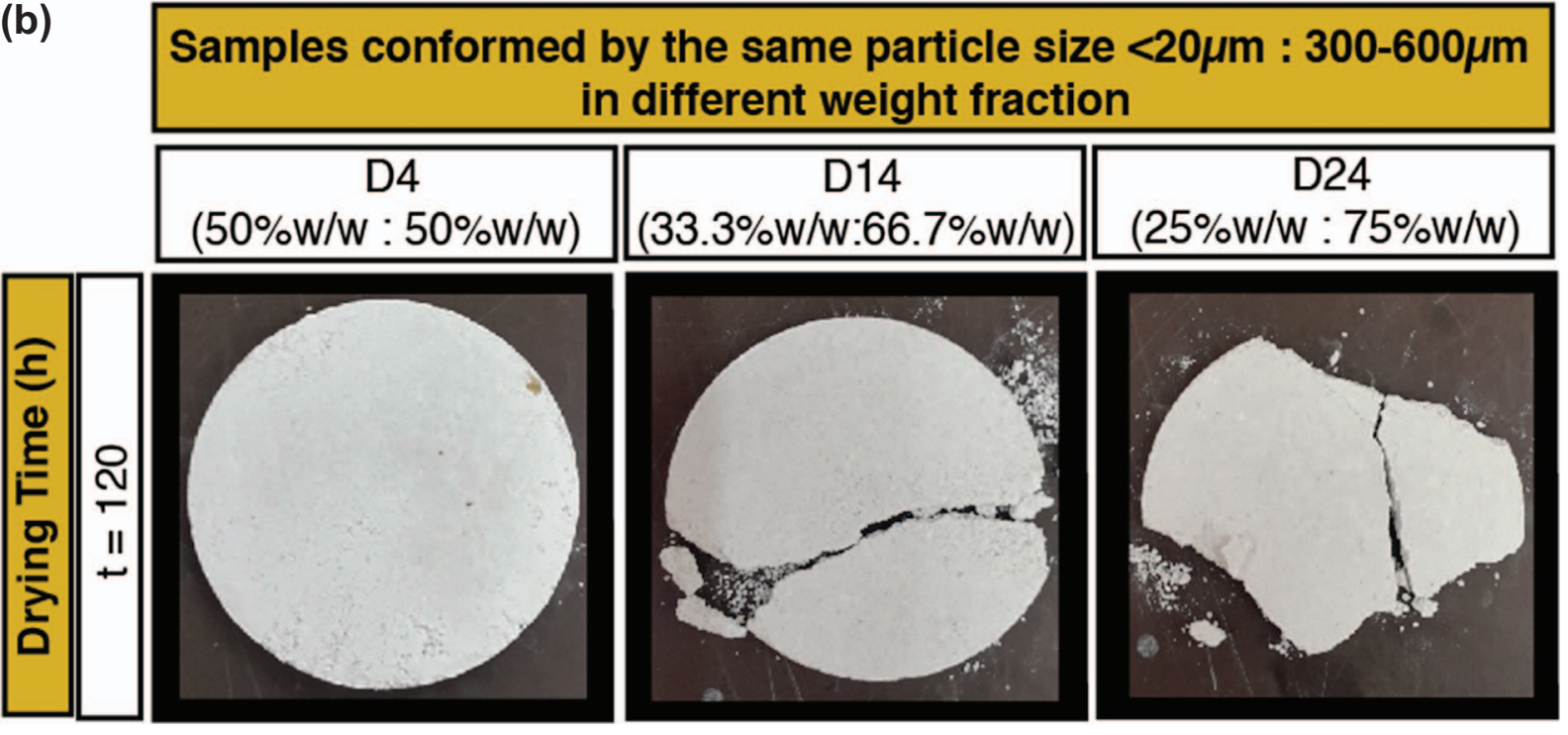

Fig. 2. Basic consolidation test of samples of disk geometry constructed without using bonding materials. (a) Comparison between resultant samples with different particle sizes and the same weight fraction. Samples D1-D10. One hundred and twenty hours after removing samples from compression molding. (b) Comparison between resultant samples with same particle sizes and different weight fraction. Samples D4, D14 and D24. One hundred and twenty hours after removing samples from compression molding.

\subsection{Consolidation by water immersion test of the samples with disk geometry composed by bonding materials}

Consolidation by water immersion tests were also carried out on samples with the same composition of those used previously for basic consolidation. Samples of disk geometry were composed by: the same quantity of base material $(5 \mathrm{~g})$, same weight fraction of combined particle size $(50 \% \mathrm{w} / \mathrm{w}$ of $<20 \mu \mathrm{m}, 50 \% \mathrm{w} / \mathrm{w}$ of $20-74 \mu \mathrm{m})$, same quantity of $\mathrm{pH} 3$ hydrochloric acid solution $(6 \% \mathrm{w} / \mathrm{w}$ relative to $5 \mathrm{~g}$ of base material) and different weight fractions of bonding materials $(5 \% \mathrm{w} / \mathrm{w}$ or $10 \% \mathrm{w} / \mathrm{w}$ relative to $5 \mathrm{~g}$ of base material). Sample D46 (5\% of slow setting gypsum), Sample D47
(10\% of slow setting gypsum), Sample D48 (5\% of fast setting gypsum); Sample D49 (10\% of fast setting gypsum); Sample D50 (5\% of stearic acid); Sample D51 (10\% of stearic acid); Sample D52 (5\% of amide wax); Sample D53 (10\% of amide wax).

Figure S5 in the Supplementary Material presents all the consolidations by water immersion results of the samples with disk geometry composed by bonding materials at 0 and $12 \mathrm{~h}$ during the test and $1 \mathrm{~h}$ after the test. Figure 6 shows these samples $1 \mathrm{~h}$ after being removed from the water immersion test. From here, similar consolidation behavior to that mentioned early for the basic consolidation test is observed: slow setting gypsum and fast setting gypsum in the two weight fractions showed poor consolidation in 


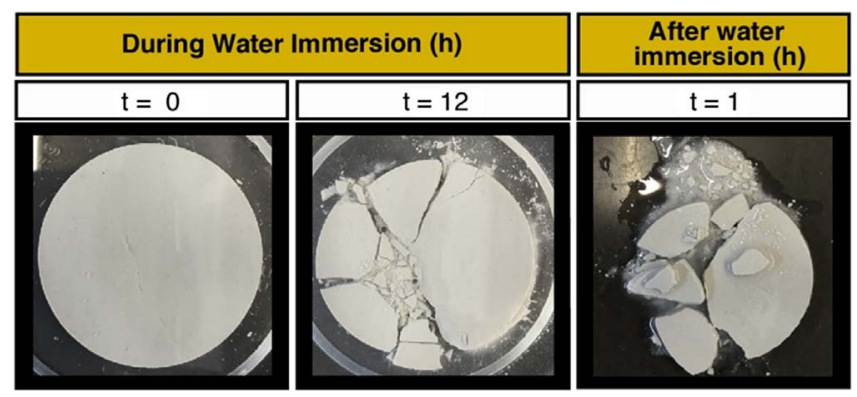

Fig. 3. Consolidation by water immersion test of the samples with disk geometry constructed without using bonding materials. Photograph register obtained during and after consolidation by water immersion test on sample D31 with disk geometry. Composition of sample D31: total quantity of $5 \mathrm{~g}$ of base material composed in weight fraction by $50 \% \mathrm{w} / \mathrm{w}$ of $<20 \mu \mathrm{m}$ and $50 \% \mathrm{w} / \mathrm{w}$ of $20-74 \mu \mathrm{m} ; 6 \% \mathrm{w} / \mathrm{w}$ (relative to $5 \mathrm{~g}$ of base material) of $\mathrm{pH} 3$ hydrochloric acid solution, and no bonding materials were used.

comparison with the samples constructed with stearic acid and commercial amide wax. On the other hand, samples constructed with stearic acid showed evidence of wormholes, probably caused by the acid effect of the bonding material on the base material.

\subsection{Basic wettability tests of the samples with disk geometry composed by bonding materials}

Based on the previous evidence of the greater basic consolidation and consolidation in water medium, samples containing stearic acid and commercial amide wax were selected to evaluate their wettability. Samples of disk geometry were composed by: the same quantity of base material $(5 \mathrm{~g})$, same weight fraction of combined particle size $(50 \% \mathrm{w} / \mathrm{w}$ of $<20 \mu \mathrm{m}, 50 \% \mathrm{w} / \mathrm{w}$ of $20-74 \mu \mathrm{m})$, same quantity of pH 3 hydrochloric acid solution $(6 \% \mathrm{w} / \mathrm{w}$ relative to $5 \mathrm{~g}$ of base material) and different weight fractions of bonding materials $(5 \% \mathrm{w} / \mathrm{w}$ or $10 \% \mathrm{w} / \mathrm{w}$ relative to $5 \mathrm{~g}$ of base material). Sample D54 (5\% of stearic acid); Sample D55 (10\% of stearic acid); Sample D56 (5\% of amide wax); Sample D57 (10\% of amide wax).

Results from wettability tests are presented in Figure 7. A tendency to obtain higher contact angles for distilled water droplets and lower contact angles for mineral oil droplets was observed in comparison to the results obtained for samples without using bonding materials. Specifically, comparing samples with bonding materials (D54-D57), higher contact angles for distilled water droplets for samples D54 and D55 with stearic acid than those for samples D56 and D57 with commercial amide wax were observed. Probably, this behavior is due to the organic compound of the stearic acid. Based on the literature, these contact angles of distilled water droplets correspond to intermediate wettability (between $50^{\circ}$ and $80^{\circ}$ ) for samples composed by commercial amide wax and oil-wet (higher than $80^{\circ}$ ) for samples composed by stearic acid. In this sense, this basic wettability test shows preliminarily that both bonding materials help in the construction of samples with similar wettability behavior to carbonate reservoir rocks from oilfields. However, dedicated wettability tests such as the Amott-Harvey index are needed to deeply understand these samples' properties.

The results previously discussed showed preliminary compositions of the synthetic samples which provide similar properties compared to natural rocks from carbonate reservoirs. This helped to guide the construction of synthetic samples with plug geometry, presented below.

\subsection{Construction and basic consolidation test of the samples with plug geometry composed by bonding materials}

To use a minimum content of bonding material while keeping an intermediate wettability of the synthetic samples and good consolidation, commercial amide wax powder at $5 \% \mathrm{w} / \mathrm{w}$ was selected to construct samples of plug geometry. Samples P1-P8 were constructed using the finest particle size combination $(<20 \mu \mathrm{m}$ mixed with $20-74 \mu \mathrm{m})$ or the thickest particle size combination $(150-300 \mu \mathrm{m}$ mixed with $300-600 \mu \mathrm{m}$ ). Samples of plug geometry (total quantity of $100 \mathrm{~g}$ of base material) were composed in weight fraction by: Samples $P 1$ and $P \mathscr{2}(50 \% \mathrm{w} / \mathrm{w}$ of $<20 \mu \mathrm{m}, 50 \% \mathrm{w} / \mathrm{w}$ of $20-74 \mu \mathrm{m}, 5 \% \mathrm{w} / \mathrm{w}$ of amide wax, $6 \% \mathrm{w} / \mathrm{w} \mathrm{pH} 3$ hydrochloric acid solution), Samples $\mathrm{P}_{3}$ and $\mathrm{P}_{4}$ $(50 \% \mathrm{w} / \mathrm{w}$ of $150-300 \mu \mathrm{m}, 50 \% \mathrm{w} / \mathrm{w}$ of $300-600 \mu \mathrm{m}$, $5 \% \mathrm{w} / \mathrm{w}$ of amide wax, $6 \% \mathrm{w} / \mathrm{w} \mathrm{pH} 3$ hydrochloric acid solution), Samples P5 and P6 $(25 \% \mathrm{w} / \mathrm{w}$ of $<20 \mu \mathrm{m}$, $75 \% \mathrm{w} / \mathrm{w}$ of $20-74 \mu \mathrm{m}, 5 \% \mathrm{w} / \mathrm{w}$ of amide wax, $6 \% \mathrm{w} / \mathrm{w}$ pH 3 hydrochloric acid solution), Samples $P^{r}$ and $P 8$ $(25 \% \mathrm{w} / \mathrm{w}$ of $150-300 \mu \mathrm{m}, 75 \% \mathrm{w} / \mathrm{w}$ of $300-600 \mu \mathrm{m}$, $5 \% \mathrm{w} / \mathrm{w}$ of amide wax, $6 \% \mathrm{w} / \mathrm{w} \mathrm{pH} 3$ hydrochloric acid solution). Figure 8 presents the constructed samples, where it is possible to observe good consolidation in terms of structural integrity. Dimensions and mass of these resultant plugs are presented in Table 5. These values were used for the theoretical porosity calculation.

\subsection{Basic wettability tests of the samples with plug geometry composed by bonding materials}

Given the previous findings, a final surface wettability study on samples of plug geometry (P1-P8) was developed. Figure 9 presents these results. A tendency to obtain higher distilled water droplet contact angles compared to mineral oil droplet contact angles was observed, probably due to the presence of the organic character of the bonding material. Samples composed of the weight fraction of $50 \%$ $\mathrm{w} / \mathrm{w}: 50 \% \mathrm{w} / \mathrm{w}$ of a base material (P1, P2, P3, P4) showed contact angles corresponding to intermediate surface wettability like those found in rocks from carbonate reservoirs. For this reason, this result suggests that the composition of these samples is the more appropriate composition for constructing synthetic samples.

\subsection{Basic petrophysical tests and theoretical porosity calculation of the synthetic samples with plug geometry composed by bonding materials}

Petrophysical analyses concerning experimental grain density, porosity, permeability, and theoretical porosity were 


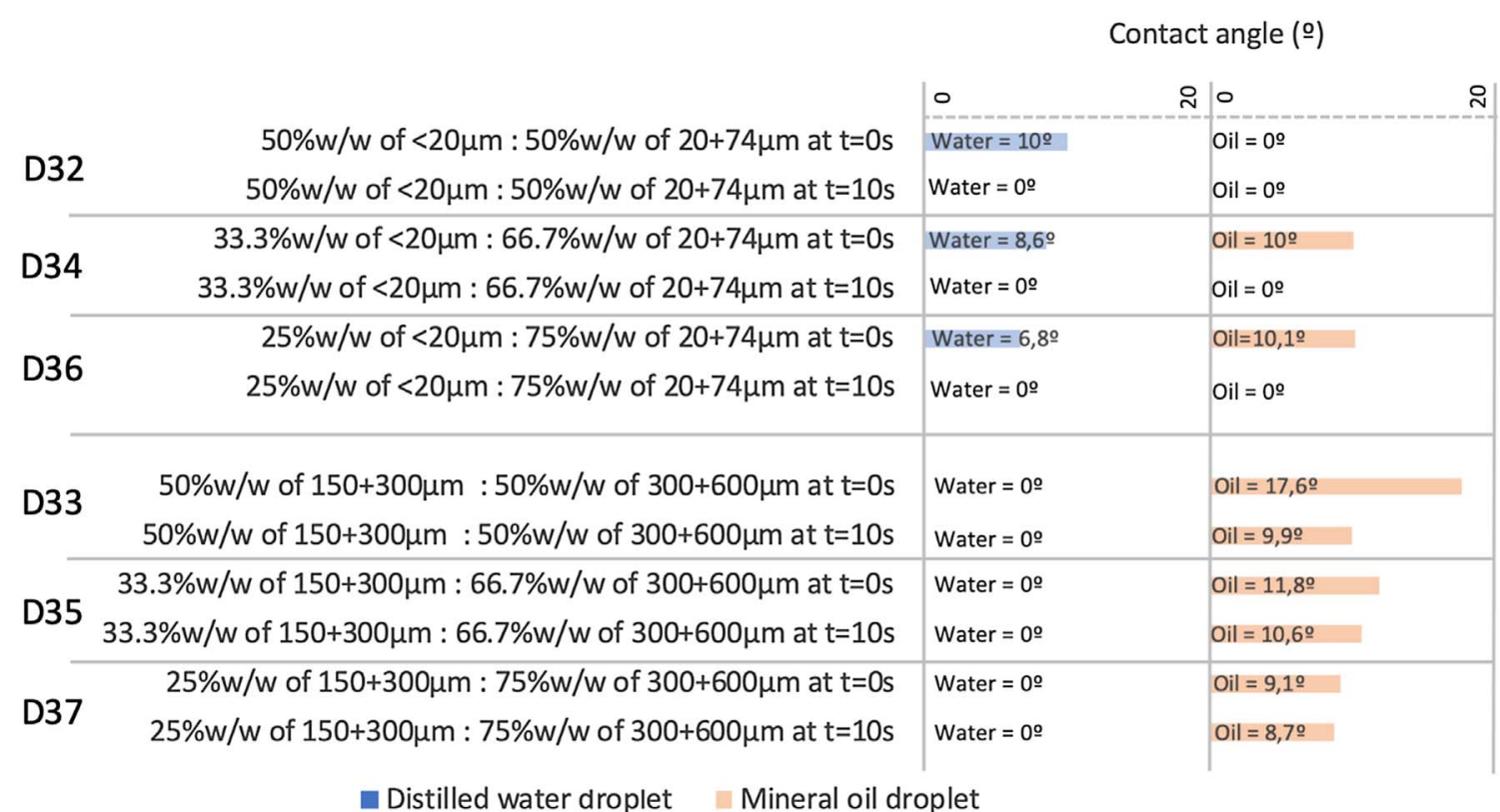

Fig. 4. Basic wettability tests of the samples with disk geometry constructed without using bonding materials. Distilled water droplet (in colour blue) and mineral oil droplet (in colour orange) contact angle measurement at times 0 and $10 \mathrm{~s}$ (after placing these droplets on the flat surface of the samples) of the samples with disk geometry D32, D33, D34, D35, D36 and D37.

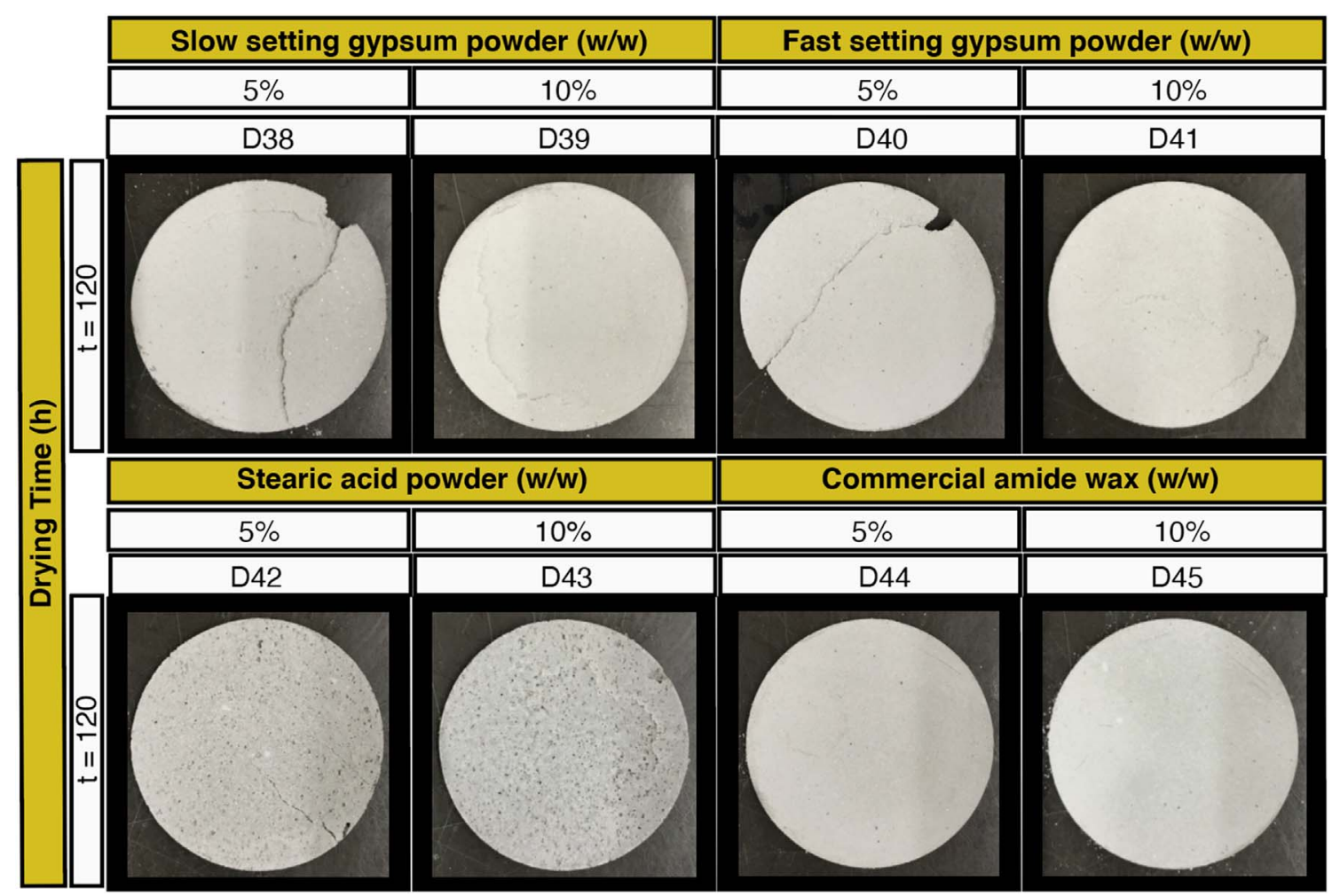

Fig. 5. Construction and basic consolidation test of the samples with disk geometry with bonding materials. Samples composed by: the same quantity of base material ( $5 \mathrm{~g})$, same weight fraction of combined particle size $(50 \% \mathrm{w} / \mathrm{w}$ of $<20 \mu \mathrm{m}, 50 \% \mathrm{w} / \mathrm{w}$ of $20-74 \mu \mathrm{m})$, same quantity of $\mathrm{pH} 3$ hydrochloric acid solution $(6 \% \mathrm{w} / \mathrm{w}$ relative to $5 \mathrm{~g}$ of base material) and different weight fractions of bonding materials $(5 \% \mathrm{w} / \mathrm{w}$ or $10 \% \mathrm{w} / \mathrm{w}$ relative to $5 \mathrm{~g}$ of base material). One hundred and twenty hours after removing samples from compression molding. 


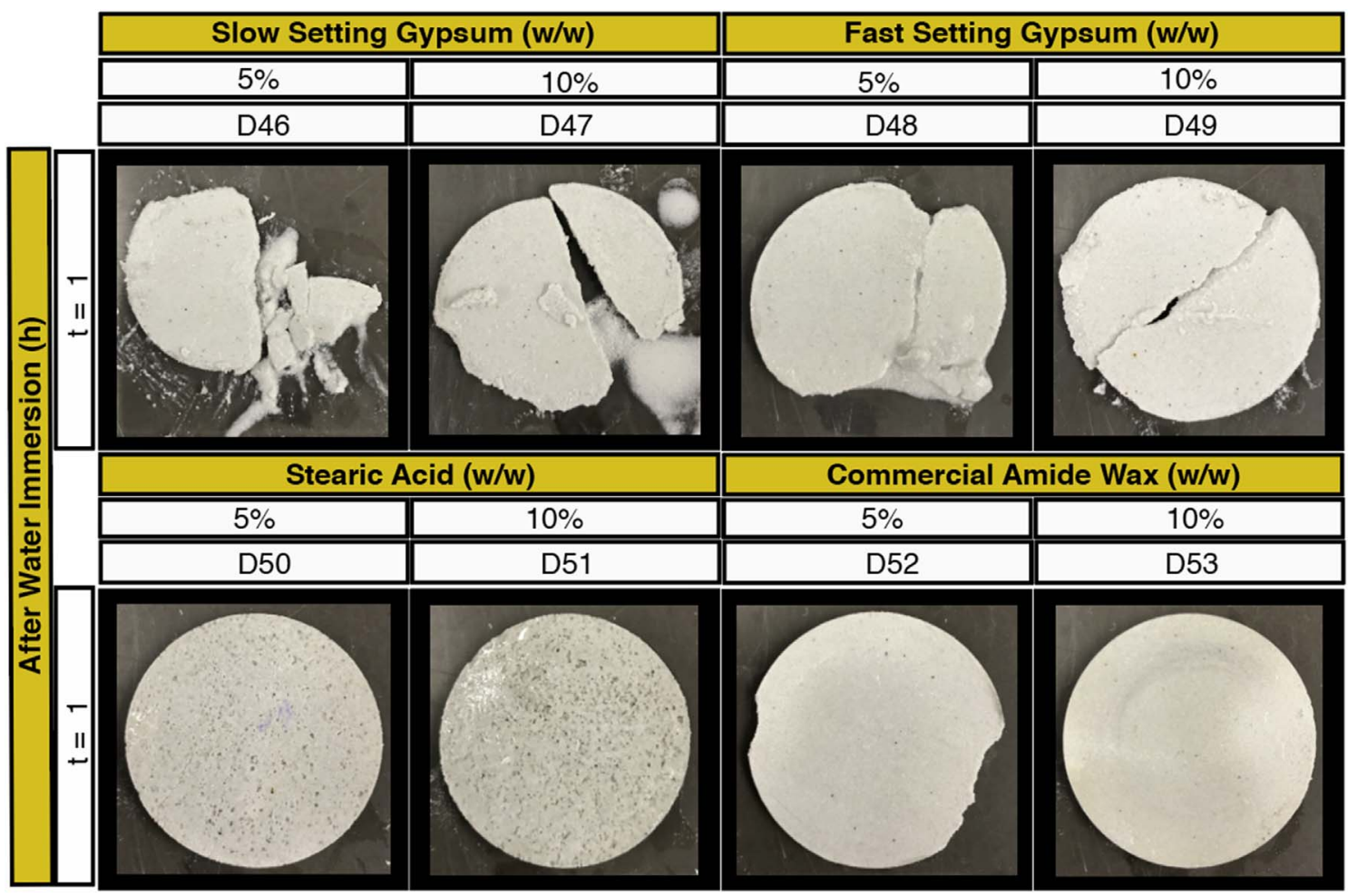

Fig.6. Photograph register of the consolidation by water immersion tests of the samples with disk geometry composed by bonding materials. Samples composed by: the same quantity of base material $(5 \mathrm{~g})$, same weight fraction of combined particle size $(50 \% \mathrm{w} / \mathrm{w}$ of $<20 \mu \mathrm{m}, 50 \% \mathrm{w} / \mathrm{w}$ of $20-74 \mu \mathrm{m})$, same quantity of $\mathrm{pH} 3$ hydrochloric acid solution $(6 \% \mathrm{w} / \mathrm{w}$ relative to $5 \mathrm{~g}$ of base material) and different weight fractions of bonding materials $(5 \% \mathrm{w} / \mathrm{w}$ or $10 \% \mathrm{w} / \mathrm{w}$ relative to $5 \mathrm{~g}$ of base material). One hour after water immersion test.

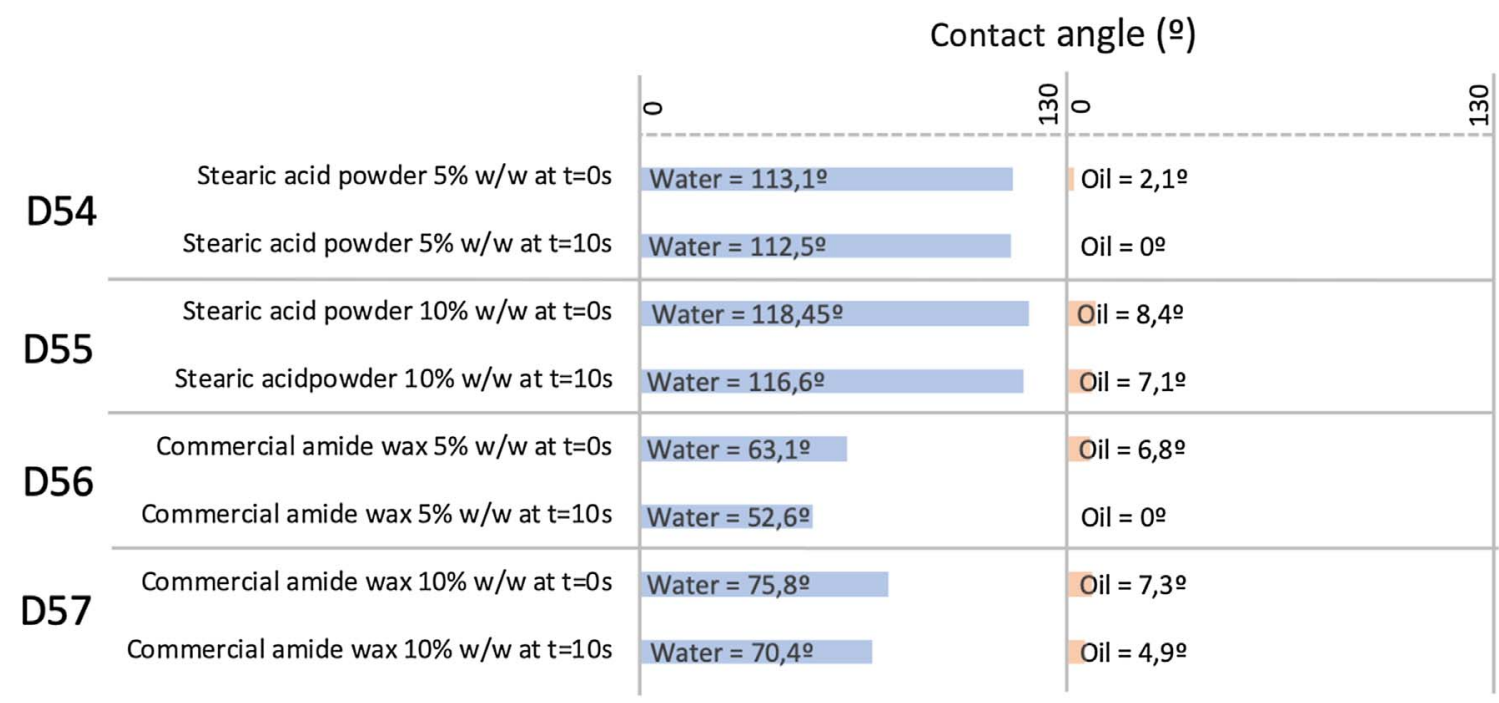

\section{Distilled water droplet Minerla Oil droplet}

Fig. 7. Basic wettability tests of the samples with disk geometry constructed without using bonding materials. Distilled water droplet (in color blue) and mineral oil droplet (in color orange) contact angle measurement at times 0 and $10 \mathrm{~s}$ (after placing these droplets on the flat surface of the samples) of the samples with disk geometry composed by: the same quantity of base material (5 g), same weight fraction of combined particle size $(50 \% \mathrm{w} / \mathrm{w}$ of $<20 \mu \mathrm{m}, 50 \% \mathrm{w} / \mathrm{w}$ of $20-74 \mu \mathrm{m})$, same quantity of pH 3 hydrochloric acid solution $(6 \% \mathrm{w} / \mathrm{w}$ relative to $5 \mathrm{~g}$ of base material) and different weight fractions of bonding materials $(5 \% \mathrm{w} / \mathrm{w}$ or $10 \% \mathrm{w} / \mathrm{w}$ relative to $5 \mathrm{~g}$ of base material). 


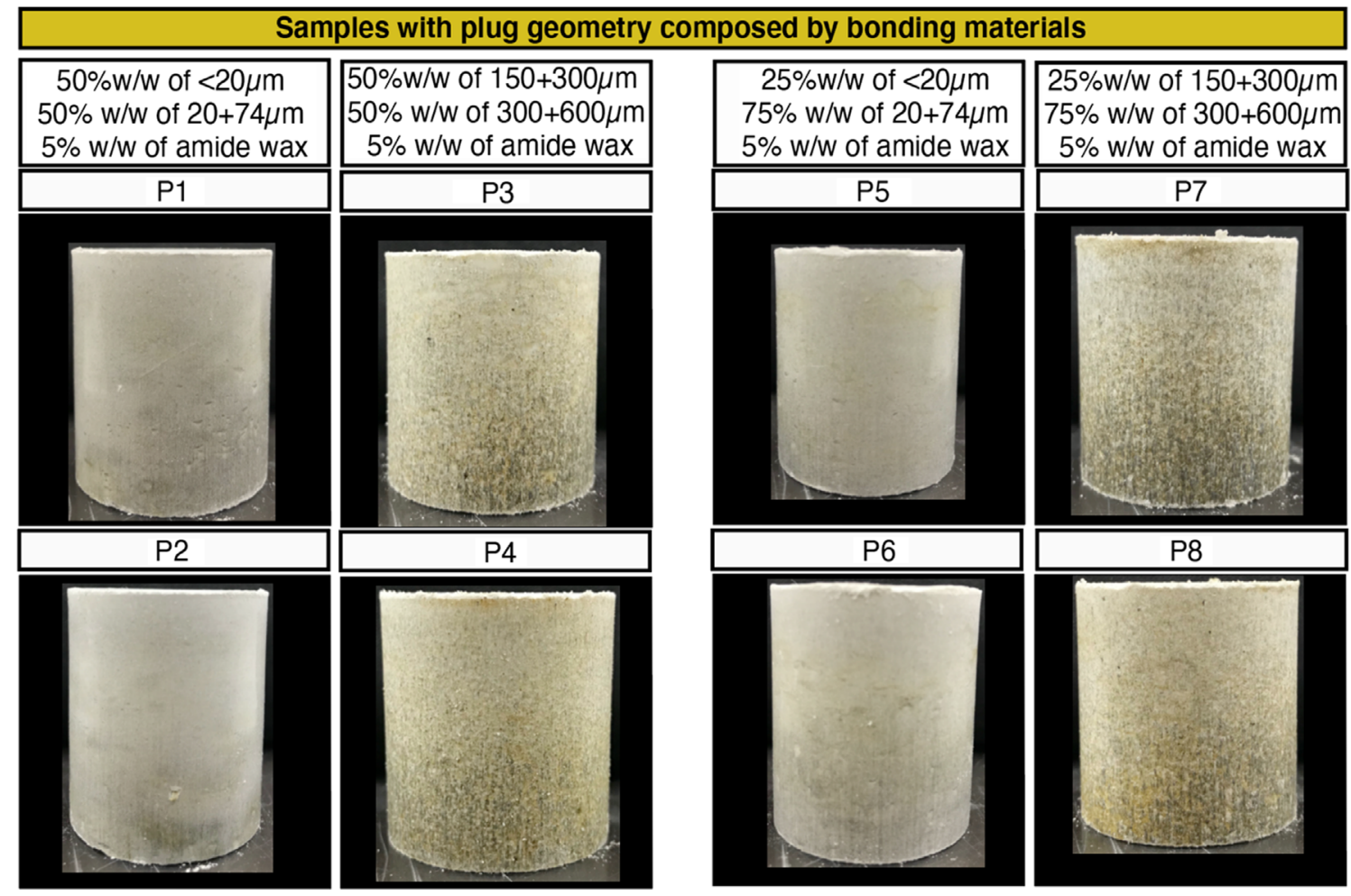

Fig. 8. Samples with plug geometry composed by bonding materials. Construction and basic consolidation of samples P1-P8. One hundred and twenty hours after removing samples from compression molding.

Table 5. Dimensions and mass of the samples with plug geometry composed by bonding materials.

\begin{tabular}{lccc}
\hline Sample & Diameter $(\mathrm{cm})$ & Height $(\mathrm{cm})$ & Mass $(\mathrm{g})$ \\
\hline P1 & 3.77 & 4.43 & 105.0371 \\
P2 & 3.77 & 4.43 & 104.2059 \\
P3 & 3.77 & 4.10 & 104.7259 \\
P4 & 3.77 & 4.11 & 104.9851 \\
P5 & 3.77 & 4.40 & 105.5181 \\
P6 & 3.77 & 4.38 & 105.5090 \\
P7 & 3.77 & 4.06 & 104.4053 \\
P8 & 3.77 & 4.07 & 104.4175 \\
\hline
\end{tabular}

analyzed for the constructed synthetic plugs. Table 6 presents these results.

Experimental grain density $\left(2.63\right.$ and $\left.2.64 \mathrm{~g} / \mathrm{cm}^{3}\right)$ of synthetic samples less than reported density in the literature for dolomite rocks $\left(2.84 \mathrm{~g} / \mathrm{cm}^{3}\right)$ is observed. This decrease of density of the synthetic samples can be explained due to the presence of the bonding material, which has a low specific gravity of 1.0 (see Tab. 1).

Experimental porosities from $10.32 \%$ to $17.23 \%$ and theoretical porosities from $12.61 \%$ to $19.88 \%$ were observed, evidencing higher values from theoretical results than from experimental results. This may probably be due to the higher confinement pressure of 2400 psi used for the experimental test in addition to the access to effective porosity by the experimental test, contrary to theoretical porosity, which considers the total porosity.

Concerning porosity (theoretical and experimental), it was observed that there is a tendency to decrease with increasing particle sizes. On the other hand, it was observed that there is an increase of absolute permeabilities with the increase of particle size. This is probably occurring due to the packing of the particles caused by smaller particles filling porous spaces between mixed larger particles, thus reducing the bulk volume occupied by the particles and, finally, increasing packing density and therefore reducing the porosity.

This basic petrophysical experimental test helped to determine the samples' composition, which provides 


\begin{tabular}{|c|c|c|c|}
\hline & & Contact a & angle (우) \\
\hline & & 0 & 10 \\
\hline 1 & $50 \% \mathrm{w} / \mathrm{w}$ of $<20 \mu \mathrm{m}, 50 \% \mathrm{w} / \mathrm{w}$ of $20+74 \mu \mathrm{m}$ and $5 \% \mathrm{w} / \mathrm{w}$ of amide wax at $\mathrm{t}=0 \mathrm{~s}$ & Water $=63,10$ & $\mathrm{Oil}=6,8 \mathrm{O}$ \\
\hline 1 & $50 \% \mathrm{w} / \mathrm{w}$ of $<20 \mu \mathrm{m}, 50 \% \mathrm{w} / \mathrm{w}$ of $20+74 \mu \mathrm{m}$ and $5 \% \mathrm{w} / \mathrm{w}$ of amide wax at $\mathrm{t}=10 \mathrm{~s}$ & Water $=52,6 \circ$ & Oil $=0$ o \\
\hline & $50 \% \mathrm{w} / \mathrm{w}$ of $<20 \mu \mathrm{m}, 50 \% \mathrm{w} / \mathrm{w}$ of $20+74 \mu \mathrm{m}$ and $5 \% \mathrm{w} / \mathrm{w}$ of amide wax at $\mathrm{t}=0 \mathrm{~s}$ & Water $=65,3$ 은 & Oil $=6,49$ \\
\hline 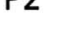 & $50 \% \mathrm{w} / \mathrm{w}$ of $<20 \mu \mathrm{m}, 50 \% \mathrm{w} / \mathrm{w}$ of $20+74 \mu \mathrm{m}$ and $5 \% \mathrm{w} / \mathrm{w}$ of amide wax at $\mathrm{t}=10 \mathrm{~s}$ & Water $=54,39$ & Oil $=0$ ? \\
\hline 3 & $50 \% \mathrm{w} / \mathrm{w}$ of $150+300 \mu \mathrm{m}, 50 \% \mathrm{w} / \mathrm{w}$ of $300+600 \mu \mathrm{m}$ and $5 \% \mathrm{w} / \mathrm{w}$ of amide wax at $\mathrm{t}=0 \mathrm{~s}$ & Water $=87,60$ & Oil $=0$ o \\
\hline & $50 \% \mathrm{w} / \mathrm{w}$ of $150+300 \mu \mathrm{m}, 50 \% \mathrm{w} / \mathrm{w}$ of $300+600 \mu \mathrm{m}$ and $5 \% \mathrm{w} / \mathrm{w}$ of amide wax at $\mathrm{t}=10 \mathrm{~s}$ & Water $=70,3^{\circ}$ & Oil $=0$ 은 \\
\hline P4 & $50 \% \mathrm{w} / \mathrm{w}$ of $150+300 \mu \mathrm{m}, 50 \% \mathrm{w} / \mathrm{w}$ of $300+600 \mu \mathrm{m}$ and $5 \% \mathrm{w} / \mathrm{w}$ of amide wax at $\mathrm{t}=0 \mathrm{~s}$ & Water $=90,39$ & Oil $=2,3$ o \\
\hline & $50 \% \mathrm{w} / \mathrm{w}$ of $150+300 \mu \mathrm{m}, 50 \% \mathrm{w} / \mathrm{w}$ of $300+600 \mu \mathrm{m}$ and $5 \% \mathrm{w} / \mathrm{w}$ of amide wax at $\mathrm{t}=10 \mathrm{~s}$ & Water $=75,49$ & Oil $=0$ o \\
\hline P5 & $25 \% \mathrm{w} / \mathrm{w}$ of $<20 \mu \mathrm{m}, 75 \% \mathrm{w} / \mathrm{w}$ of $20+74 \mu \mathrm{m}$ and $5 \% \mathrm{w} / \mathrm{w}$ of amide wax at $\mathrm{t}=0 \mathrm{~s}$ & Water $=57,39$ & Oil $=7,2$ o \\
\hline & $25 \% \mathrm{w} / \mathrm{w}$ of $<20 \mu \mathrm{m}, 75 \% \mathrm{w} / \mathrm{w}$ of $20+74 \mu \mathrm{m}$ and $5 \% \mathrm{w} / \mathrm{w}$ of amide wax at $\mathrm{t}=10 \mathrm{~s}$ & Water $=40,5$ & $\mathrm{Oil}=6,4^{\circ}$ \\
\hline & $25 \% \mathrm{w} / \mathrm{w}$ of $<20 \mu \mathrm{m}, 75 \% \mathrm{w} / \mathrm{w}$ of $20+74 \mu \mathrm{m}$ and $5 \% \mathrm{w} / \mathrm{w}$ of amide wax at $\mathrm{t}=0 \mathrm{~s}$ & Water $=58,12$ & Oil $=7,19$ \\
\hline & $25 \% \mathrm{w} / \mathrm{w}$ of $<20 \mu \mathrm{m}, 75 \% \mathrm{w} / \mathrm{w}$ of $20+74 \mu \mathrm{m}$ and $5 \% \mathrm{w} / \mathrm{w}$ of amide wax at $\mathrm{t}=10 \mathrm{~s}$ & Water $=39,30$ & Oil $=6,5$ o \\
\hline P7 & $25 \% \mathrm{w} / \mathrm{w}$ of $150+300 \mu \mathrm{m}, 75 \% \mathrm{w} / \mathrm{w}$ of $300+600 \mu \mathrm{m}$ and $5 \% \mathrm{w} / \mathrm{w}$ of amide wax at $\mathrm{t}=0 \mathrm{~s}$ & Water $=87,9^{\circ}$ & $\mathrm{Oil}=10,20$ \\
\hline & $25 \% \mathrm{w} / \mathrm{w}$ of $150+300 \mu \mathrm{m}, 75 \% \mathrm{w} / \mathrm{w}$ of $300+600 \mu \mathrm{m}$ and $5 \% \mathrm{w} / \mathrm{w}$ of amide wax at $\mathrm{t}=10 \mathrm{~s}$ & Water $=27,10$ & Oil $=9,70$ \\
\hline P8 & $25 \% \mathrm{w} / \mathrm{w}$ of $150+300 \mu \mathrm{m}, 75 \% \mathrm{w} / \mathrm{w}$ of $300+600 \mu \mathrm{m}$ and $5 \% \mathrm{w} / \mathrm{w}$ of amide wax at $\mathrm{t}=0 \mathrm{~s}$ & Water $=73,7^{\circ}$ & Oil $=9,40$ \\
\hline & $25 \% \mathrm{w} / \mathrm{w}$ of $150+300 \mu \mathrm{m}, 75 \% \mathrm{w} / \mathrm{w}$ of $300+600 \mu \mathrm{m}$ and $5 \% \mathrm{w} / \mathrm{w}$ of amide wax at $\mathrm{t}=10 \mathrm{~s}$ & Water $=30,49$ & Oil $=6,19$ \\
\hline
\end{tabular}

Fig. 9. Basic wettability tests of the samples with disk geometry constructed without using bonding materials. Distilled water droplet (in color blue) and mineral oil droplet (in color orange) contact angle measurement at time 0 and $10 \mathrm{~s}$ (after placing these droplets on the flat surface of the samples) of the samples with plug geometry P1, P2, P3, P4, P5, P6, P7, P8.

Table 6. Experimental grain density, porosity, absolute permeability, and theoretical porosity of the synthetic samples with plug geometry.

\begin{tabular}{lcccc}
\hline Sample & \multicolumn{2}{c}{$\begin{array}{c}\text { Experimental petrophysics results obtained by nitrogen porosimetry } \\
\text { measurements }\end{array}$} & Theoretical porosity (\%) \\
\cline { 2 - 4 } & Grain density $\left(\mathrm{g} / \mathrm{cm}^{3}\right)$ & Porosity $(\%)$ & Absolute permeability $(\mathrm{mD})$ & \\
\hline P1 & 2.63 & 17.07 & 0.073 & 19.24 \\
P2 & 2.63 & 17.23 & 0.093 & 19.88 \\
P3 & 2.63 & 10.66 & 0.671 & 13.00 \\
P4 & 2.64 & 10.43 & 0.723 & 12.99 \\
P5 & 2.64 & 14.67 & 0.131 & 18.31 \\
P6 & 2.64 & 14.58 & 0.135 & 12.29 \\
P7 & 2.64 & 10.47 & 0.717 & 12.61 \\
P8 & 2.64 & 10.32 & 0.683 & \\
\hline
\end{tabular}

porosities of the synthetic samples $(10.32-17.23 \%)$ and absolute permeabilities $(0.073-0.723 \mathrm{mD})$ in the previously desired petrophysical range for this work, similar to some Brazilian pre-salt oil fields (porosities between $6 \%$ and $28 \%$, permeabilities between 0.1 and $10000 \mathrm{mD}$ ). These preliminary results will help to guide further dedicated petrophysical studies in synthetic samples such as mercury intrusion porosimetry, scanning electron microscopy and X-ray microtomography.

\subsection{Final remarks}

This preliminary analysis of consolidation, wettability and petrophysics helped to determine some compositions of synthetic samples which reach a range of properties close to natural rocks from carbonate reservoirs. In this sense, this procedure could be an alternative to the well-known difficulty of obtaining reservoir carbonate plugs. The results presented in this study will guide further dedicated analyses, such as Amott-Harvey index, mercury intrusion porosimetry, scanning electron microscopy and X-ray micro-computed tomography, among others, to deeply understand the samples' properties.

\section{Conclusion}

Based on the evidenced wettability and petrophysics properties of the synthetic samples, which reach a range values 
similar to natural rocks from carbonate reservoirs, and the good consolidations of the samples, the recommended compositions to construct synthetic samples of plug geometry are:

Composition 1: Total quantity of $100 \mathrm{~g}$ of base material $(50 \% \mathrm{w} / \mathrm{w}$ of $<20 \mu \mathrm{m}, 50 \% \mathrm{w} / \mathrm{w}$ of $20-74 \mu \mathrm{m})+5 \% \mathrm{w} / \mathrm{w}$ of amide wax (relative to $100 \mathrm{~g}$ of base material) $+6 \%$ $\mathrm{w} / \mathrm{w}$ (relative to $100 \mathrm{~g}$ of base material) of $\mathrm{pH} 3$ hydrochloric acid solution.

Composition 2: Total quantity of $100 \mathrm{~g}$ of base material $(50 \% \mathrm{w} / \mathrm{w}$ of $150-300 \mu \mathrm{m}, 50 \% \mathrm{w} / \mathrm{w}$ of $300-600 \mu \mathrm{m})+$ $5 \% \mathrm{w} / \mathrm{w}$ (relative to $100 \mathrm{~g}$ of base material) of amide wax $+6 \% \mathrm{w} / \mathrm{w}$ (relative to $100 \mathrm{~g}$ of base material) of pH 3 hydrochloric acid solution.

In addition to the compositions, it is necessary to follow the reported procedure based on the sample's drying temperature of $100{ }^{\circ} \mathrm{C}$ for $1 \mathrm{~h}$ and uniaxial compaction with controlled load force $(200 \mathrm{kN})$ and velocity $(25 \mathrm{~mm} / \mathrm{min})$ aiming to obtain similar samples to those reported here.

These preliminary results will guide further dedicated petrophysical and wettability analyses to deeply understand these samples' properties and enhance the construction of synthetic samples more similar to natural rocks from carbonate reservoirs.

Acknowledgments. The authors would like to thank the following Polytechnic School Laboratories of the University of São Paulo for the facilities and sponsorship given to conduct part of the research activities: Fundo Patrimonial Amigos da Poli, LCT (Laboratório de Caracterização Tecnológica), LFQI (Laboratório de Fenômenos de Transporte e Química de Interfaces Aplicados à Engenharia Mineral), LPTC (Laboratório de Processos Cerâmicos), Petrobras S.A and Laboratório de Sedimentologia e Estratigrafia - Santos-SP.

\section{Supplementary Materials}

The supplementary material of this article is available at https://ogst.ifpenergiesnouvelles.fr/10.2516/ogst/2020087/ olm

Table S1: Composition and approaches of each sample.

Figure S1: Resulting synthetic samples of disk geometry composed by: total quantity of $5 \mathrm{~g}$ of base material for each sample, combination of particle size in weight fraction of $50 \% \mathrm{w} / \mathrm{w}$.

Figure S2: Resulting synthetic samples of disk geometry composed by: total quantity of $5 \mathrm{~g}$ of base material for each sample, combination of particle size in weight fraction of $33.3 \% \mathrm{w} / \mathrm{w}$.

Figure S3: Resulting synthetic samples of disk geometry composed by: total quantity of $5 \mathrm{~g}$ of base material for each sample, combination of particle size in weight fraction of $25 \% \mathrm{w} / \mathrm{w}$.

Figure S4: Construction and basic consolidation test of the samples with disk geometry with bonding materials.

Figure S5: Photograph register of the consolidation by water immersion tests of the samples with disk geometry composed by bonding materials.

\section{References}

Alotaibi M.B., Azmy R., Nasr-el-din H.A. (2010) Wettability challenges in carbonate reservoirs, in: SPE Improved Oil Recovery Symposium, 24-28 April, Tulsa, Oklahoma, USA. SPE-129972-MS. https://doi.org/10.2118/129972-MS.

Anbah S.A., Chilingar G.V., Beeson C.M. (1965) Application of electrical current for increasing the flow rate of oil and water in a porous medium, J. Can. Petrol. Technol. 4, 2, 81-88. PETSOC-65-02-05. https://doi.org/10.2118/65-02-05.

ANP (2018a) Badejo reservoir. Available: <http://www.anp.gov. $\mathrm{br} /$ images/EXPLORACAO E PRODUCAO DE OLEO E_GAS/Gestao_Contratos/Fase_Producao/Planos Desenvolvimento/Sumario_Executivo_Externo_Badejo.pdf $>$. Accessed October 2018.

ANP (2018b) Bicudo reservoir. Available: < http://www.anp. gov.br/images/planos_desenvolvimento/Bicudo.pdf $>$. Accessed October $201 \overline{8}$.

ANP (2018c) Bonito reservoir. Available: < http://www.anp. gov.br/images/planos_desenvolvimento/Bonito.pdf $>$. Accessed October $201 \overline{8}$.

ANP (2018d) Garoupa reservoir. Available: <http://www. anp.gov.br/images/planos_desenvolvimento/Garoupa.pdf $>$. Accessed October 2018.

ANP (2018e) Linguado reservoir. Available: <http://www.anp.gov. br/images/planos desenvolvimento/Linguado.pdf $>$. Accessed October 2018.

ANP (2018f) Pampo reservoir. Available: <http://www.anp. gov.br/images/planos_desenvolvimento/Pampo.pdf $>$. Accessed October $201 \overline{8}$.

ANP (2018g) Piranema reservoir, Available: < http://www.anp. gov.br/images/planos_desenvolvimento/Piranema.pdf $>$. Accessed October $201 \overline{8}$.

ANP (2018h) Siri reservoir. Available: <http://www.anp.gov.br/ images/planos_desenvolvimento/Siri.pdf $>$. Accessed October 2018.

ANP (2018i) Trilha reservoir. Available: < http://www.anp. gov.br/images/planos_desenvolvimento/Trilha.pdf $>$. Accessed on October 2018 .

Barbassa A.G. (2007) Fato Relevante, Análise da Área de Tupi, Petrobras. Available <http://siteempresas.bovespa.com.br/ consbov $/$ arquivosexibe.asp? Site $=\&$ protocolo $=140478>$. Accessed 6 June 2018.

Bernard G.G. (1967) Effect of floodwater salinity on recovery of oil from cores containing clays, in: SPE California Regional Meeting, 26-27 October, Los Angeles, California. SPE-1725MS. https://doi.org/10.2118/1725-MS.

Celis L.A., Fernandez O.D. (2012) Estudio experimental de procesos de inyección de agua en el equipo de desplazamiento radial con medios porosos estratificados, Rev. Fuentes 10, 2, 71-80.

Cosentino L. (2001) Integrated reservoir studies, Editions Technip, Paris.

Dolomite Mineral Data (2018) Available: <http://webmineral. com/data/Dolomite.shtml>. Accessed on April 2018.

Ehrenberg S.N., Nadeau P.H. (2005) Sandstone vs. carbonate petroleum reservoirs: A global perspective on porosity-depth and porosity-permeability relationships, AAPG Bull. 89, 4, 435-445. https://doi.org/10.1306/11230404071.

Fedrizzi R.M., Rodrigues M.A., Missagia R.M., Santos V.H., Neto I.L. (2018) Artificial carbonate rocks: synthesis and petrophysical characterization, J. Petrol. Sci. Eng. 163, 303-310. https://doi.org/10.1016/j.petrol.2017.12.089. 
Florez J.J.A., Ferrari J.V., Michelon M., Ulsen C. (2019) Construction of synthetic carbonate plugs: A review and some recent developments, Oil Gas Sci. Technol. - Rev. IFP Energies nouvelles 74, 29. https://doi.org/10.2516/ogst/2019001.

Furre A.K., Holt R.M. (1995) Anisotropy of a synthetic layered porous medium, in: SEG Annual Meeting, 8-13 October, Houston, Texas SEG-1995-0898.

Gaafar G.R., Tewari R.D., Zain Z.M. (2015) Overview of advancement in core analysis and its importance in reservoir characterization for maximizing recovery, in: SPE Asia Pacific Enhanced Oil Recovery Conference, 11-13 August, Kuala Lumpur, Malaysia. SPE-174583-MS. https://doi.org/10.2118/ 174583-MS.

Grate J.W., Dehoff K.J., Marvin G.W., Pittman J.W., Wietsma T.W., Zhang C., Oostrom M. (2012) Correlation of oil-water and air-water contact angles of diverse silanized surfaces and relationship to fluid interfacial tensions, Langmuir 28, 18, 7182-7188. https://doi.org/10.1021/la204322k.

Greaves M., Wilson A., Al-Honi M., Lockett A.D. (1996) Improved recovery of light/medium heavy oils in heterogeneous reservoirs using air injection/in-situ combustion (ISC), in: SPE Western Regional Meeting, 22-24 May, Anchorage, Alaska. SPE-35693-MS. https://doi.org/10.2118/35693-MS.

Lakatos I., Toth J., Bauer K., Lakatos-Szabo J., Palasthy G., Wöltje H. (2003) Comparative study of different silicone compounds as candidates for restriction of water production in gas wells, in: International Symposium on Oilfield Chemistry, 5-7 February, Houston, Texas. SPE-80204-MS. https://doi. org/10.2118/80204-MS.

Lowell S., Shields J.E., Thomas M.A., Thommes M. (2004) Characterization of porous solids and powders: Surface area, pore size and density, Springer, London, England. https://doi. org/10.1007/978-1-4020-2303-3.

Luo P., Knorr K.D., Nakutnyy P., Crabtree M. (2018) A novel coreless injectivity technique for evaluating formation damage in argillaceous reservoirs, in: SPE Improved Oil Recovery Conference, 14-18 April, Tulsa, Oklahoma, USA. SPE190152-MS. https://doi.org/10.2118/190152-MS.

Luquot L., Gouze P., Niemi A., Bensabat J., Carrera J. (2016) $\mathrm{CO}_{2}$-rich brine percolation experiments through Heletz reservoir rock samples (Israel): Role of the flow rate and brine composition, Int. J. Greenhouse Gas Control 48, 1, 44-58. https://doi.org/10.1016/j.ijggc.2015.10.023.

Pizarro J.O.D.S., Branco C.C.M. (2012) Challenges in implementing an EOR project in the pre-salt province in deep offshore Brasil, in: SPE EOR Conference at Oil and Gas West Asia, 16-18 April, Muscat, Oman. SPE-155665-MS. https://doi.org/10.2118/155665-MS.

Raimondi P., Torcaso M.A. (1964) Distribution of the oil phase obtained upon imbibition of water, SPE J. 4, 1, 49-55. SPE570-PA. https://doi.org/10.2118/570-PA.

Souza F.D., Bragança S.R. (2013) Caracterização tecnológica de um calcário dolomítico in natura, calcinado e sulfatado como meio dessulfurante, Cerâmica 59, 350, 331-337. https://doi. org/10.1590/S0366-69132013000200020.

Tanikawa W., Shinamoto T. (2006) Klinkenberg effect for gas permeability and its comparison to water permeability for porous sedimentary rocks. Hydrology and earth system science discussions, J Hydrol. Earth Syst. Sci. Discuss. 3, 1315-1338. https://doi.org/10.5194/hessd-3-1315-2006.

Tarek T.A. (2014) Petrophysical characterization of the effect of xanthan, Master's Thesis, Dalhousie University.

Wang W., Zhang X., Geng X., Chang Q. (1997) Experimental investigation on the dielectric constant of rocks with low porosity and permeability, SPE Adv. Technol. Ser. 5, 1, 115119. SPE-30871-PA. https://doi.org/10.2118/30871-PA.

Wang R., Chen Z., Qin J., Zhao M. (2008) Performance of drainage experiments with Orinoco Belt heavy oil in a long laboratory core in simulated reservoir conditions, SPE J. 13, 4, 474-479. SPE-104377-PA. https://doi.org/10.2118/ 104377-PA.

Wang Z., Wang R., Li T., Zhao M. (2017) The combined effects of pore structure and pore fluid on the acoustic properties of cracked and vuggy synthetic rocks, J. Petrol. Sci. Eng. 156, 202-211. https://doi.org/10.1016/j.petrol.2017.05.023.

Xu Y., Lu M. (2011) Microbially enhanced oil recovery at simulated reservoir conditions by use of engineered bacteria, $J$. Petrol. Sci. Eng. 78, 2, 233-238. https://doi.org/10.1016/j. petrol.2011.06.005. 